\title{
EFFECT OF FREEZE DRYING PROCESS ON SOME PROPERTIES OF STREPTOCOCCUS THERMOPHILUS ISOLATED FROM DAIRY PRODUCTS
}

\author{
Krishan K. Selwal ${ }^{*}$, Manjit K. Selwal ${ }^{2}$, D.N. Gandhi ${ }^{3}$
}

\begin{abstract}
${ }^{1}$ Department of Biotechnology, DCR University of Science and Technology, Murthal-131039 Haryana, (India); ${ }^{2}$ Department of Biotechnology, Kurukshetra University, Kurukshetra-136119, Haryana, (India); ${ }^{1,3}$ Dairy Microbiology Division, National Dairy Research Institute, Karnal-132001 Haryana, (India).
\end{abstract}

Submitted: September 21, 2010; Returned to authors for corrections: February 18, 2011; Approved: May 30, 2011.

\begin{abstract}
The present investigation represents the effect of freeze drying on some properties as acid and bile tolerance of Streptococcus thermophilus MTCC 1938 culture isolated from dairy products. The cell paste obtained from milk based medium was freeze dried with a pressure of $50-100$ mtorr for $24 \mathrm{~h}$ at $-40^{\circ} \mathrm{C}$. Acid and bile tolerance test exhibited 3.8-4.9 and 3.2-3.8 log counts reduction after freeze drying respectively.
\end{abstract}

Key words: Acid and Bile tolerance, Cryoprotective agent, Streptococcus thermophilus

Commercial lactic acid bacteria (LAB) have been widely used for the manufacture of fermented milk products and the inclusion of probiotic microorganism in dairy products is a usual practice, in order to increase their health beneficial effect. Streptococcus thermophilus is used, along with other microorganisms, as a starter culture for the manufacture of several important fermented dairy foods, including yogurt, acidophilus bio-yogurt, and mozzarella cheese (7).

In recent time, preservation of starter cultures through freeze-drying has gained prominence within the dairy industry. Nevertheless, during the drying process, the cells undergoes through harsh environmental conditions, causing detrimental effects on the cells. The major contributory factors responsible for viability loss are osmotic shock and membrane injury, due to intracellular ice formation and recrystallization. To protect the cells from these injuries, certain cryoprotective agents, like polysaccharide, polyols, sugar alcohol, amino acid, peptides, and proteins are used $(6,11)$. However, few reports are available on the influence of freeze drying on potential properties of $S$. thermophilus cultures (4).

The main objective of this work was to study the relevant properties, including acid, bile tolerance, cell surface hydrophobicity, and antimicrobial activity of a $S$. thermophilus culture isolated from dairy products London, before and after freeze drying.

To achieve our objectives, a culture of S. thermophilus (MTCC 1938) was obtained from Microbial Type Culture Collection (MTCC), Chandigarh, India. Cell biomass was produced in a $5 \mathrm{~L}$ capacity fermenter (Bio-Age International, Chandigarh, India) with working volume of $3.5 \mathrm{~L}$, in the SYG medium, composed of skim milk (11\% Non Fat Milk Solid, (Experimental dairy plant, NDRI, Karnal ); 0.5\% (w/v) yeast

\footnotetext{
*Corresponding Author. Mailing address: Department of Biotechnology, DCR University of Science and Technology, Murthal -131039, Haryana, (India).; Tel.: +91-9416989067 Fax no-130-2484004.; E-mail: krishan.kselwal@gmail.com
} 
extract (Hi-media, Mumbai, India) and 1.5\% (w/v) glucose (Hi-media, Mumbai, India). The cells from the growth medium were harvested by centrifugation at $10,000 \mathrm{rpm}$ for 10 minutes (Sigma, Rotor No-11250) and suspended in equal volume of sterilized SSMG cryoprotective solution composed of skim milk supplemented with 7\% sucrose (Hi-Media, Mumbai, India), 1.5\% gelatin (Hi-Media, Mumbai, India) and $1 \mathrm{M}$ (Molar) monosodium glutamic acid (Hi-media, Mumbai, India). The mixtures were frozen at $-80^{\circ} \mathrm{C}$ overnight and then freeze-dried using freeze dryer (Christ Alpha D-37520, Germany) under the pressure of 50-100 mtorr for $24 \mathrm{~h}$ at $-40^{\circ} \mathrm{C}$. The buffers used in the study were: PUM buffer $(\mathrm{g} / \mathrm{l})$ : $\mathrm{K}_{2} \mathrm{HPO}_{4} .3 \mathrm{H}_{2} \mathrm{O}: 22.20 ; \mathrm{KH}_{2} \mathrm{PO}_{4}: 7.26$; Urea: 1.80; $\mathrm{MgSO}_{4}$ : 0.20; $\mathrm{pH}$ : 7.10. Saline solution (g/l) $\mathrm{NaCl}: 8.50$.

Acid tolerance of $S$. thermophilus (before and after freeze drying) was studied at different $\mathrm{pH}$ solutions. The solutions were prepared by adjusting the hydrochloric acid $(\mathrm{HCl})$ solution to $\mathrm{pH}$ levels of $1.5,2.0$ and 3.0 in distilled water. Sterile double distilled water $(\mathrm{pH}$ 6.5) served as control. Ten $\mathrm{ml}$ of each $\mathrm{pH}$ solution was taken in sterilized test tubes and mixed with $0.1 \mathrm{~g}$ of freeze dried powder of the culture containing about $10^{8}-10^{9} \mathrm{CFU} / \mathrm{ml}$. One $\mathrm{ml}$ from each $\mathrm{pH}$ solution was taken immediately $(0 \mathrm{~h})$ and after $1,2,3 \mathrm{~h}$ of incubation and serial dilutions were prepared using sterile saline solution.

Similarly, bile tolerance was studied by preparing $1 \%$ and $2 \%$ bile salt solutions. Sterile double distilled water without bile salt was used as control. Ten $\mathrm{ml}$ of each solution was transferred into sterile test tubes and mixed with fresh, as well as freeze dried cells of $S$. thermophilus containing approx. $10^{8}$ $10^{9} \mathrm{CFU} / \mathrm{mL}$. The tubes were then incubated at $37^{\circ} \mathrm{C}$ aerobically. One $\mathrm{ml}$ of culture was taken out from each tube immediately $(0 \mathrm{~h})$, after 3,8 , and $12 \mathrm{~h}$ incubation period. Serial dilutions were prepared in sterile saline blanks, plated on M17 agar and incubated for $72 \mathrm{~h}$ at $37^{\circ} \mathrm{C}$.

Cell surface hydrophobicity was determined by growing freeze dried cells in M17 broth (Hi-Media, Mumbai, India)

under aerobic conditions for $16-18 \mathrm{~h}$ at $37^{\circ} \mathrm{C}$. The cells were harvested by centrifugation at 7,000 rpm for $10 \mathrm{~min}$, washed twice in Phosphate Urea Magnesium (PUM) buffer and finally suspended in the same buffer. Four milliliter suspension bearing initial absorbance (A) of 0.8-0.9 at $600 \mathrm{~nm}$ was mixed with $0.8 \mathrm{ml} \mathrm{n}$-hexadecane and vortexed at high speed for 2-3 min. The mixture was left undisturbed for $1 \mathrm{~h}$ at $37^{\circ} \mathrm{C}$ to allow the phase separation. The lower aqueous phase was carefully removed with a sterile Pasteur pipette and final absorbance $\left(\mathrm{A}_{\mathrm{o}}\right)$ was recorded. The decreased absorbance in aqueous phase was taken as measure of cell surface hydrophobicity $(\mathrm{H} \%)$ and calculated using following equation:

$\mathrm{H} \%=\quad \underline{\mathrm{A}-\mathrm{Ao}} \times 100$

A.

Antagonistic activity of $S$. thermophilus was assessed by using agar well assay method against Vibrio cholarae MTCC 3906, Staphylococcus aureus NCDC 110, Escherichia coli NCDC -135, Shigella sp. AIIMS, Salmonella sp MTCC 3219 according to Anand et al [1]. Cell free supernatant (CFS) was obtained by inoculating the culture in skim milk and incubate it at $37^{\circ} \mathrm{C}$ for $10-12 \mathrm{~h}$. The cells were harvested by centrifugation at $10,000 \mathrm{rpm}$ for $15 \mathrm{~min}$. The resulting supernatant was carefully removed and $30 \mu \mathrm{l}$ of CFS was added in the well of Nutrient Agar medium (Hi-Media, India) previously inoculated with $0.5 \mathrm{ml}$ of pathogenic culture (containing $10^{7}-10^{8}$ $\mathrm{CFU} / \mathrm{mL}$ ). The diameter of the test strain growth inhibition zone was measured.

Acid and bile salts tests were performed in triplicates. Data were analyzed by using the one way analysis of variance (ANOVA) procedure of SYSTAT 6.0.1 (Statistical Software Package, 1996, SPSS, Inc., USA). Significant differences between means were calculated by using Duncan's multiple range tests, where means of triplicate values were stated significantly different when the probability level was $(p<0.05)$

The tested organism showed a steady loss in viability 
when exposed to acidic conditions. Fresh cells of $S$. thermophilus (before freeze drying) showed better tolerance at low $\mathrm{pH} 1.5$ and survive up to $2 \mathrm{~h}$ (Fig. 1a), suggesting it is having some probiotic properties. After drying of cells, significant reduction $(\mathrm{P}<0.05)$ in cell counts took place at all $\mathrm{pH}$ solutions. The culture tolerated $\mathrm{pH}$ 3.0 and 2.0 well with 5.3 and $5.1 \log \mathrm{cfu} / \mathrm{ml}$, but exhibited poor tolerance to $\mathrm{pH} 1.5$ and lost about 3.5-5.5 log count of cells after 3 $\mathrm{h}$ of incubation (Fig. 1b). Most microorganisms are destroyed by low $\mathrm{pH}$ and hydrochloric acid in the stomach. In human, the time from entrance to release from the stomach was reported to be 90 min and the bactericidal effect of the acid is evident at $\mathrm{pH}$ values below 2.5 (2). Hence, the survival of $S$. thermophilus culture was studied under in vitro conditions imitating the physicochemical events occurring in the gastrointestinal tract. The incubation time chosen for acid and bile tolerance tests was $3 \mathrm{~h}$ and $12 \mathrm{~h}$ respectively, simulating the residence time in the human stomach. This finding was supported by studies of Khalil (5), indicating that the death of the streptococcal strains at $\mathrm{pH} 1.5$ was higher. The survival of $S$. thermophilus CHCC 3534 strain was higher in comparison to our study. This could be explained by the difference in the test protocol and intrinsic difference between the two strains.
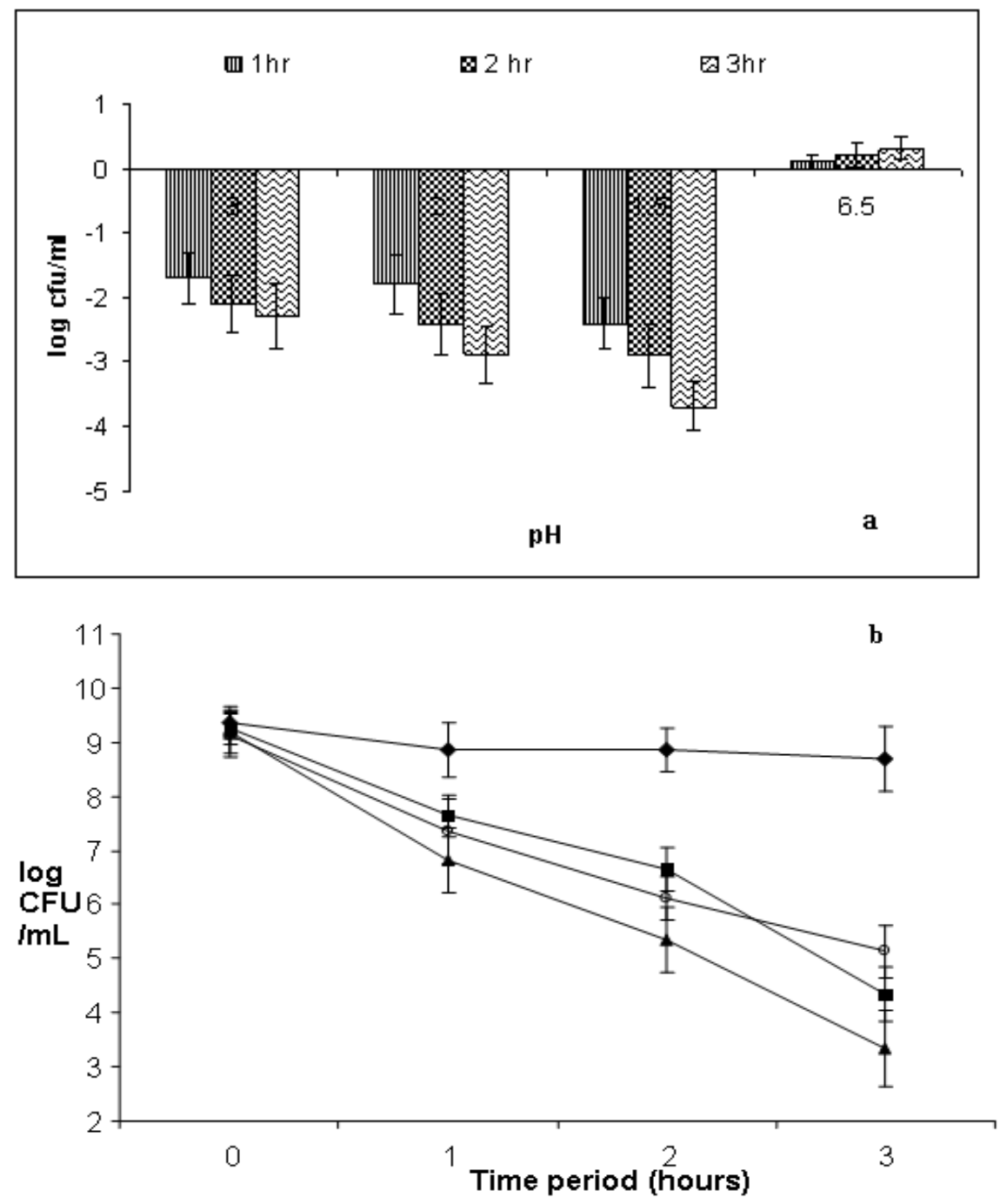

Figure 1. Acid tolerance of S. thermophilus culture (a) Before freeze drying (b) After freeze drying at [o]-pH 3 [ $]-\mathrm{pH} 2[\mathbf{\Delta}]-$ $\mathrm{pH} 1.5[\bullet]-$ Control. Bars represent standard error of mean value of triplicate experiments. 
Similarly, fresh cells (prior to freeze-drying) tended to have slightly better tolerance to all bile solutions than the freeze-dried cells. The cell counts were in the range of 9.0-9.3 $\log \mathrm{CFU} / \mathrm{mL}$ and about 2.2-3.5 log count decreased after the bile salt treatment (Fig. 2a). Freeze-drying had no effect on the bile tolerance in the conditions tested. The culture showed considerable tolerance as it gave a viable count of 5.9 and $5.2 \log \mathrm{CFU} / \mathrm{mL}$ after $12 \mathrm{~h}$ of incubation at $1 \%$ and $2 \%$ bile concentrations, respectively, after freeze drying (Fig. 2b). However, the control showed continuous increase in cell counts up to $12 \mathrm{~h}$ of incubation. The loss in viability was higher in $2 \%$ of bile salt concentration $(3.5 \mathrm{log}$ $\mathrm{CFU} / \mathrm{mL}$ reductions after $12 \mathrm{~h}$ ) than $1 \%$ bile salt concentration. This behavior indicates some possible properties of this strain as a probiotic microorganism, since it survived at $2 \%$ bile salt solution, which is equivalent to the physiological concentration in the duodenum (3, 12). Furthermore, the drying conditions caused some injury to the cells and thus increased the possibilities for their viability loss.
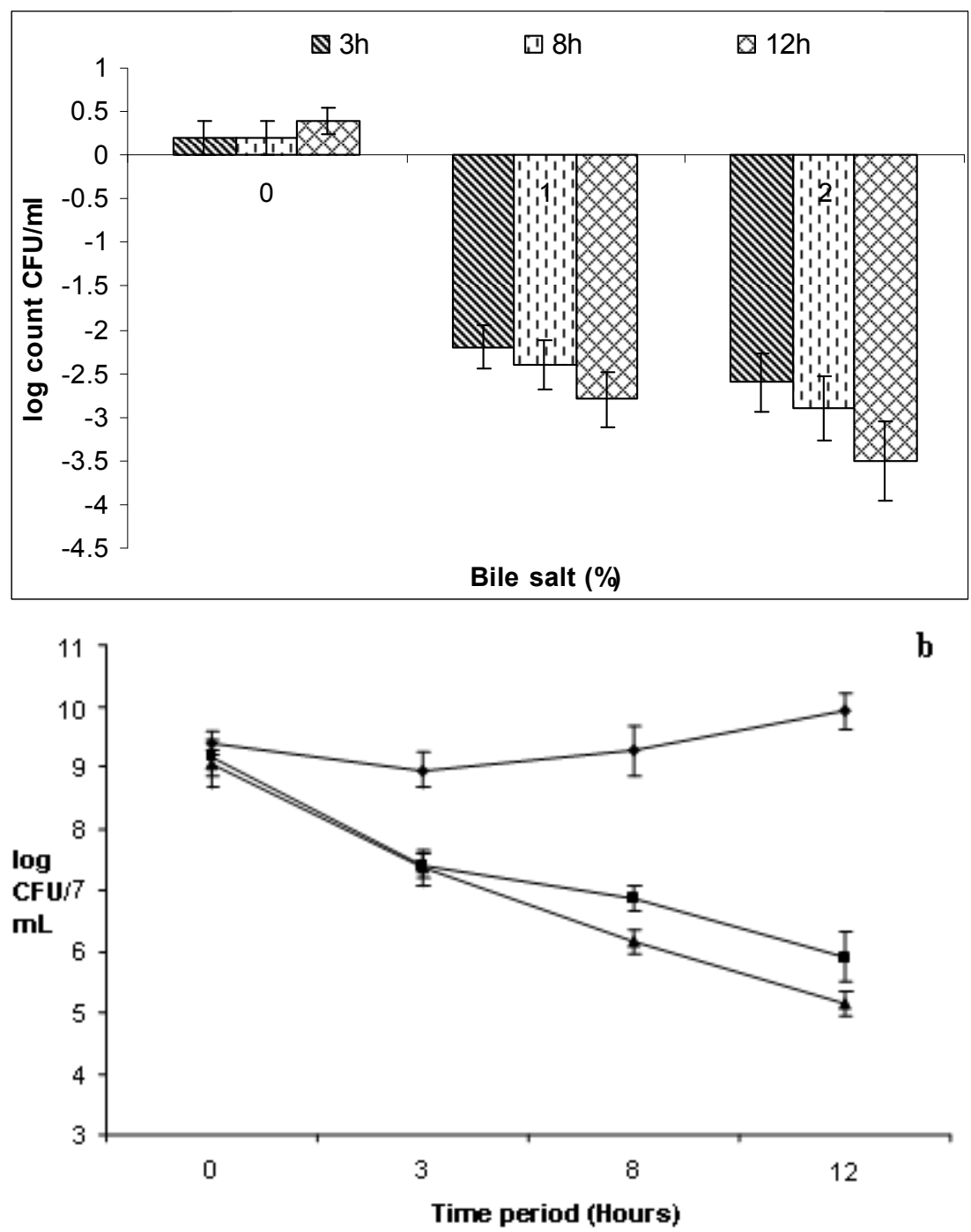

Figure 2. Bile tolerance of $S$. thermophilus culture (a) Before freeze drying (b) After freeze drying at [ $\bullet-0 \%$ Bile concentration (control) $[\mathbf{\square}]-1 \%$ Bile concentration [ $\boldsymbol{\Delta}$ ] - 2\% Bile concentration. Bars represent standard error of mean value of triplicate experiments. 
Hydrophobicity results revealed that the culture had $4.7 \% \pm 0.4$ hydrophobicity towards n-hexadecane and no significant difference was observed between fresh and dried cells. In our study, cell surface hydrophobicity was found to be lower. The results were in accordance with that of reported by Owehand et al (8). Furthermore, incubation time, adhesion buffer, growth conditions, and growth medium influence the cell surface hydrophobicity very significantly. The validity of results from in vitro adhesion assays remains extremely uncertain in the case of hydrophobocity (9).

The agar well-diffusion method results (Table I) showed that the crude CFS had moderate activity against Escherichia coli and Vibirio cholarae, since these strains were strongly inhibited (10 and $9 \mathrm{~mm}$ inhibition zone size respectively). No activity was observed against other pathogenic strains. The production levels and the proportion of inhibitory compounds depend on the strain, medium compounds and physical parameters. From our study, we suggest that the organism probably controlled the growth of pathogens through the production of inhibitory compounds, such as lactic acid, acetic acid and formic acid.

Table 1. Antimicrobial activity of cell free supernatants of $S$. thermophilus against common pathogens. (-): No zone was observed

\begin{tabular}{lc}
\hline \multicolumn{1}{c}{ Indicator Organisms } & Zone of Inhibition \\
\hline Staphylococcus aureus NCDC 110 & - \\
Escherichia coli NCDC -135 & $10 \mathrm{~mm}$ \\
Vibirio cholarae MTCC 3906 & $9 \mathrm{~mm}$ \\
Shigella sp AIIMS & - \\
Salmonella sp MTCC 3219 & - \\
\hline
\end{tabular}

The result demonstrated that the freeze drying process yield a powdery form of culture and has little impact on the acid and bile tolerance properties. Optimization of the production process and the cryoprotective agents are the most important factors. However, a better way of using the strain is as a support culture consisting of non probiotic strain or a yoghurt culture (10). In conclusion, the culture showed some promising probiotic properties and further tests and in-vivo study must be carried out to confirm its probiotic attributes.

\section{ACKNOWLEDGEMENTS}

The senior research fellowship under Rajiv Gandhi National Fellowship scheme (University Grant Commission) sponsored by the Ministry of Social Justice \& Empowerment and Ministry of Tribal Affairs, Govt. of India to the first author is gratefully acknowledged.

\section{REFERENCES}

1. Anand, S.K.; Srinivasan, R.A.; Rao, L.K. (1984). Antibacterial activity associated Bifidobacterium bifidum. J. Cult. Dairy Prod. 19, 6-8

2. Berrada, N.; Lameland, J.F.; Laroche, G. (1991). Bifidobacterium from fermented milks: Survival during gastric transit. J. Dairy Sci. 74, 409413.

3. Brashears, M.M.; Gilliland, S.E.; Buck, L.M. (1998). Bile salt deconjugation and cholesterol removal from media by Lactobacillus casei. J. Dairy Sci. 81, 2103- 2110.

4. Giulio, B.D.; Orlando, P.; Barba1, G.; Coppola, R.; De Rosa, M.; Sada, A.; De Prisco, P.P.; Nazzaro, F. (2005). Use of alginate and cryoprotective sugars to improve the viability of lactic acid bacteria after freezing and freeze-drying. World J. Microbiol. Biotechnol. 21, 739-746.

5. Khalil, R.K. (2009). Evidence for probiotic potential of a capsular producing Streptococcus thermophilus CHCC 3534 strain. Afr. J. Microbiol. Res. 3(1), 027-034.

6. Kumar, K.; Gandhi, D.N. (2009). Innovative techniques in the starter culture preservation: A review. J. Food Sci. Technol. 46(3), 190-195.

7. Mater, D.G.; Bretigny, L.; Firmesse, O.; Flores, M.; Mogenet, A.; Bresson, J.; Corthier, G. (2005). Streptococcus thermophilus and Lactobacillus delbreukii subsp. bulgaricus gastrointestinal transit of healthy volunteers consuming yoghurt. FEMS Microbiol. Lett. 250, 185187.

8. Ouwehand, A.C.; Kirjavainen, P.V.; Gronlund, M.M.; Isolauri, E.; Salminen, S.J. (1999). Adhesion of probiotic micro-organisms to intestinal mucus. Int. Dairy J. 9, 623-30.

9. Ouwehand, A.C.; Salminen, S. (2003). In vitro adhesion assays for probiotics and their in vivo relevance: a Review. Microb. Ecol. in Health 
and Dis. 15, 4175-4184.

10. Saxelin, M.; Grenov, B.; Svensson, U.; Fonden, R.; Reniero, R.; Mattila, S.T. (1999). The technology of Probiotics. Trends Food Sci. Technol. 10, 387-392.

11. Selwal, K.K.; Selwal, M.K.; Gandhi, D.N. (2010). Effect of cryoprotective agents on survival and beta-galactosidase activity of $L$. acidophilus and S. thermophilus. Milchwissenschaft 66(1) -25-28.

12. Yateem, A.; Balba, M.T.; Al-Surrayai, T.; Al-Mutairi, B.; Al-Daher, R. (2008). Isolation of Lactic acid bacteria with probiotic potential from camel milk. Int. J. Dairy Sci. 3(4), 194-199.

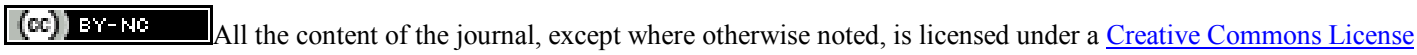

